\title{
Assessment of the implementation of step-by-step adult basic life support sequence by emergency medical technicians and drivers during regular annual training
}

\author{
SLADJANA ANDJELIĆ ${ }^{1}$, ZORAN RADOJICIC ${ }^{2}$, SRDJAN STOJANOVIC ${ }^{1}$, VLADA TAMBURKOVSKI \\ 1 Emergency Medical Services, Belgrade, Serbia \\ 2 University of Belgrade, Faculty of Organizational Sciences, Belgrade, Serbia
}

Corresponding author

Sladjana Andjelic

Franse d'Eperea 5

11000 Belgrade, Serbia

Phone: +381641245757

E-mail:novizivot94@gmail.com

\section{ABSTRACT}

Objective. Evaluation of the efficiency of practicing step-by-step (SBS) BLS/AED (basic life support/automatic external defibrillator) sequence by emergency medical technicians (EMT) and ambulance drivers (AD) working in medical transport teams. Methods. A prospective two-month study was conducted in which EMTs and ADs working in medical transport teams performed their regular 4-hour annual training ( $1 \mathrm{~h}$ of lectures, $1.5 \mathrm{~h}$ of practical training and $1.5 \mathrm{~h}$ of testing). Each participant performed SBS of BLS/AED sequences in front of a three-member team of instructors. The implementation of BLS/AED sequence was evaluated by scoring from 0 to 2 ( 0 - not, 1 - partially, 2 - properly), separately for EMTs, ADs and in total. The final analysis compared a properly implemented SBS sequence (S1-S36) of actions: IA initial assessment (S1-S10), BLS (S11-S18), AED (S19-S25), RP - recovery position (S26-S32) and FBAO - foreign body airway obstruction (S33-S36) for use by the BLS/ AED between EMTs and ADs. The criterion for a completed regular training was at least $47(65.0 \%)$ of the total number of points won for properly implemented procedures.

Results. The study involved 31 EMTs and 63 Ads, regardless of gender and average age, with EMTs having slightly longer work experience $(p>0.05)$. The results of our study show that EMTs are more skilled at IA, cardiopulmonary resuscitation (CPR) and AED, whereas ADs were better at implementing RP and performing the Heimlich maneuver $(\mathrm{p}<0.001)$.

Conclusion. Although EMTs and ADs implement SBS BLS/AED procedures correctly and satisfactorily in more than $65.0 \%$, future research should focus on finding more efficient, shorter and cheaper BLS/AED trainings.

Key words: basic life support, step-by-step, sequence, emergency medical technicians, ambulance drivers

\section{INTRODUCTION}

In economically developed countries, sudden cardiac arrest (SCA) is the third most common killer, right after cardiovascular diseases and cancer. (1) It is estimated that in Europe only at least 2,000 people die from SCA every day, due to unsuccessful cardiopulmonary resuscitation. (CPR) Cardiopulmonary resuscitation is the first line treatment and foundation for saving lives following cardiac arrest. (2) Unfortunately, no emergency medical service (EMS) in the world - regardless of how well it is organized - can always reach a person with SCA within 3 to 5 minutes. But it can at least be sufficiently well trained to provide basic life support (BLS) measures to anyone, anywhere and at any time, even if that is outside the workplace and without adequate medical equipment. (3) The goal of implementing BLS/AED (advanced life support) skills is to introduce uniform criteria in SCA diagnostics and treatment, both by unqualified people with no formal medical education and by medical workers in the role of eyewitnesses. The most recent recommendations of the European Resuscitation Council (ERC) in 2015, in the field of education, emphasized the importance of training EMS teams and the implementation of acquired knowledge and skills in everyday medical practice. (4)

This work aims to assess the effectiveness of practical performance of step-by-step BLS and the use of an automatic external defibrillator (AED) by EMTs and ambulance drivers $(\mathrm{AD})$ working in medical transportation and hemodialysis teams, during their regular annual training.

\section{MATERIALS AND METHODS}

\section{Study design}

One of the activities of EMS in Belgrade is the medical transport of immobile or hard-to-move patients, and patients included in regular hemodialysis program, between home and hospital in both directions. In these teams (without doctors), there are 31 EMTs and 63 ADs. Together with emergency medical teams, they form part of EMS. Their work obligations are defined in their individual work contracts, but also proceed from EMS Annual Work Plan (EMS AWP). According to this EMS AWP, all medical (doctors and EMTs) and non-medical (ADs) workers of EMS are obliged to carry out their regular annual training in BLS/AED for adults.

\section{Study subjects}

A prospective two-month study was conducted (March 1 - May 1, 2017). A list of four trainees was prepared for each day and they carried out their regular annual four-hour training in the Training Center (1 hour of lectures, 1.5 hours of practical 
training and 1.5 hours of testing). They were trained by the Center instructor to apply BLS and AED measures according to current guidelines from 2015. The lectures concerned the recognition of cardiac arrest in adults, chain of survival, update on BLS, airway obstruction by a foreign body, recovery position and the use of AED.

After the demonstration, the participants trained practical skills at workshops. Stepby-step BLS/AED sequences and actions were practiced by simulating cardiac arrest on a demonstration manikin: IA - initial assessment (S1-S5), BLS - basic life support measures i.e. compression of the sternum and artificial ventilation (S6-S18), AED the use of automated external defibrillator (S19-S25), RP - putting the unconscious person in recovery position (S26-S32) and FBAO - management of foreign body airway obstruction (S33-S36).

In the final 90 minutes of training, each participant individually performed stepby-step sequences of BLS/AED actions. To avoid subjectivity, a team of instructors (3 members) was formed, that jointly assessed the implementation of the sequence of procedures by scoring from 0 to 2 points (0 - not implemented, 1 - partially, 2 properly implemented). The scoring table (Table 1) was previously prepared according to figure 2.4. Step by step sequence of actions for use by the BLS/AED trained provider to treat the adult cardiac arrest victim, which can be found in Section 2 of Adult basic life support and automated external defibrillation according to European Resuscitation Council Guidelines for Resuscitation 2015. (5) Reliability analysis for questionnaire Cronbach's alpha were 0.724 . Cronbach's alpha of more than 0.7 means acceptable questionnaire. Kendall's coefficient of concordance $w=0.991$ shows a high level of agreements $(p<0.001)$ between items.

Resusci Anne Skill guide Full-Body Basic provided CPR measurement and feedback during training. The information obtained was related to the following CPR performances: correct hand position and compression depth, rate, incomplete release, correct inflation volume, excessive inflation and too rapid inflation.

The criterion for a completed regular training was at least 47 (65.0\%) of the total number of points won for properly performed procedures. Categorization of the implementation of certain step-by-step sequences/actions was done by summarizing data (Not implemented, Partially implemented, Properly implemented), separately for EMTs, ADs and in total. The final analysis compared properly implemented step-by-step sequence (S1-S36) of actions: IA (S1-S10), BLS (S11-S18), AED (S19S25), RP (S26-S32) and FBAO (S33-S36) for use by the BLS/AED between EMTs and ADs.

\section{Statistics}

Collected data were based on CAI (Computer Assisted Interview) methodology. The statistical analysis was performed using SPSS (V.16.0, SPSS Inc., Chicago, IL, USA) package for Windows, graph presentations using Harvard Graphics. Exploratory data analysis was used for descriptive statistics (frequencies, mean, standard deviation, median etc.). Numerical data (years, total test scores, etc.) were checked for the normal distribution $(p>0.05)$ and tested using Student's t-test. Categorical data were cross - compared using Pearson's Chi-Square test or Likelihood Ratio test. Validation of the questionnaire Cronbach's alpha and Kendall's coefficient of concordance were used. $\mathrm{P}$ values $<0.05$ were considered statistically significant for all statistical analysis.

\section{RESULTS}

The study population consisted of 31 EMTs and 63 ADs, who were all of the same gender (all men) and of similar average age $(44,06 \pm 10.05$ EMTs vs $42.52 \pm 9.24$ Ads, $\mathrm{p}>0.05$ ), with EMTs having slightly longer work experience $(21.84 \pm 10.13$ vs $17.84 \pm 10.39)$ in EMS $(p<0.05)$. Table 2 shows the estimated practical implementation of BLS skills (step by step S1-S36) of EMTs and ADs, individually and collectively.

One hundred per cent implementation of actions was registered in sequences $\mathrm{S} 9$ (RP decisions) and S13 (compression depth) for both EMT and AD groups. The EMTs implemented S26 and S27 (the first two RP steps) with $100.0 \%$ accuracy, and the ADs showed the same result for actions number S29 and S30 (roll the victim towards the rescuer). Both groups partially or fully adopted actions from the following sequences: check response (S4), check breathing (S8), CPR decision (S10), compression depth (S13), compression rate (S14), roll the victim towards the rescuer (S29, S30), CPR start (S36). Only the EMT group adopted the actions from sequences: ventilation (S15, S16), deliver shock (S22), first two RP steps (S26, S27), and only the $\mathrm{AD}$ group adopted the actions from sequence number S35 (Heimlich maneuver). The percentage of actions not implemented was significantly higher in the $\mathrm{AD}$ group for sequences $\mathrm{S} 1$ : danger, safety, protective equipment (79.4\%) and S2 - patient's position $(68.3 \%)$, whereas in total a high percentage of actions not implemented was recorded for sequences S11 - calling 194 (79.8\%) and S24 - continue CPR (66.0\%). Figures from 1 to 5 show the ratio of properly implemented CPR/AED performances (S1-S36) between EMTs and ADs: Figure 1 - IA (S1-S10); Figure 2 - BLS (S11-S18), Figure 3 - AED (S19-S25), Figure 4 - RP (S26-S32), and Figure 5 - FBAO (S32S36). It can be noticed that the EMTs are more skilled than the ADs $(\mathrm{p}<0.001)$ in the IA (Figure 1), the application of CPR (Figure 2) and the use of AED (Figure 3). Figure 4 shows that, although in the initial steps (S26 and S27) in the RP there is no difference between the EMTs and the $\mathrm{ADs}$, the $\mathrm{ADs}$ are better at implementing further procedures of the RP between S28 and S32. In suspected FBAO (Figure 5), the ADs implement the proper procedures of the Heimlich maneuver (S35) in a much higher percentage $(\mathrm{p}<0.001)$.

\section{DISCUSSION}

According to the available literature, this is the first study to compare BLS/AED skills between EMTs and ADs working in EMS medical transport teams. If a patient suffers an SCA during medical transport, EMTs, as the only medical workers present (these teams perform without doctors), have to be able to recognize SCA, take and implement the appropriate BLS/AED measures until the arrival of resuscitation team. Their partners in those procedures are ADs. BLS/AED skills are crucial for their everyday operation. The need for a bridging course focused on the knowledge and skills necessary for these target groups (EMTs and ADs) to become efficient members of medical transport teams, resulted in the introduction of regular annual training in Belgrade EMS. To improve BLS/AED performances, the use of feedback devices (6) such as Resusci Anne Skill guide used in our study is proposed. Several authors described the problem of poor performance in CPR, even when provided by medical professionals. (7) Miotto et al. demonstrated that older health professionals show decreased knowledge retention of psychomotor and cognitive abilities. However, despite the older age, the group that received conventional BLS training (group B) performed better in the practical test. The results of our study show that EMTs are more skilled at the initial exami- 


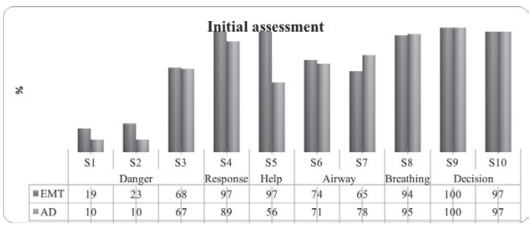

Figure 1. Initial assessment, properly implemented steps

$\mathrm{AD}$, ambulance driver; EMT, emergency medical technician

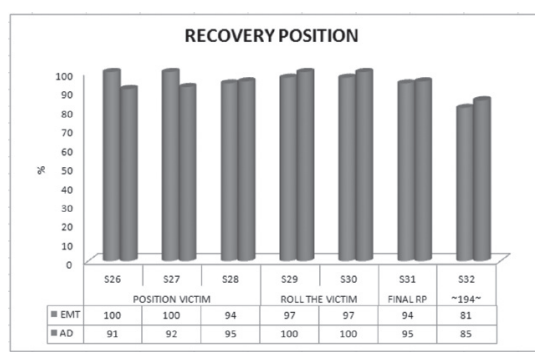

Figure 4. Recovery position (RP), properly implemented steps

$\mathrm{AD}$, ambulance driver; EMT, emergency medical technician

nation, $\mathrm{CPR}$ and $\mathrm{AED}$, whereas $\mathrm{ADs}$ are better at implementing recovery position procedures and the Heimlich manoeuvre. (8) Emergency medical practitioners need to be well aware of and familiar with new knowledge in the field of CPR. (9)

On the other hand, Miotto et al. demonstrated that theoretical training alone was not able to produce good quality CPR, especially regarding manoeuvres such as airway opening; ventilation; correct positioning of the hands; adequate chest compressions and ventilation-compression cycles. Batcheller AM et al. concluded that CPR performance of subjects over forty is better following a half-hour, selfinstruction video compared to traditional four-hour classroom training. (9) It is understandable that, by training and selfconfidence gained during education and as team leaders in EMS teams without doctors, EMTs have greater inventiveness and ability than $\mathrm{ADs}$ to independently manage SCA. According to our study, EMTs' practical skills are satisfactory, although there is room for further improvement in BLS/ AED.

The number of participants in practical training should be limited to enable equal

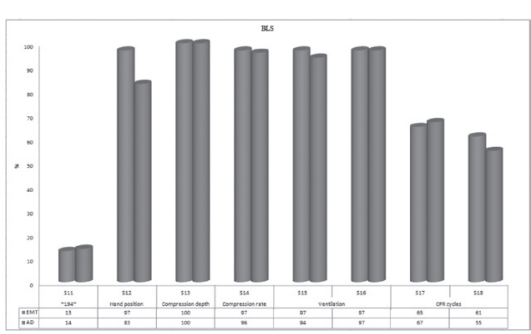

Figure 2. Basic life support (BLS), properly implemented steps

$\mathrm{AD}$, ambulance driver; EMT, emergency medical technician

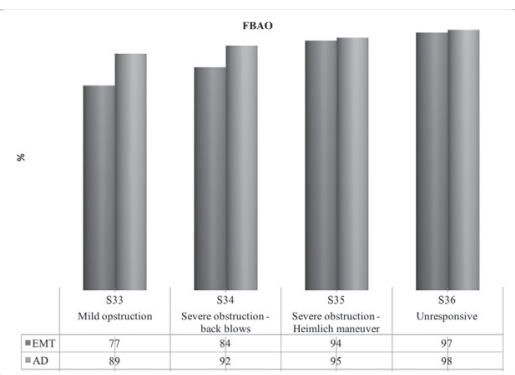

Figure 5. Foreign body airway obstruction (FBAO), properly implemented steps

$\mathrm{AD}$, ambulance driver; EMT, emergency medical technician

and high-grade acquisition of necessary BLS skills. The best results are achieved in small groups such as ours (from 4 to 8 ) and bigger number of workshops. $(10,11)$

However, it has been proved that CPR skills get lost within a month of training, so that projected annual retrainings, like those in our study, are often not enough. While optimal intervals are not known, a frequent "low dose" retraining may be beneficial. (12) Frequent "low-dose" training may improve $\mathrm{CPR}$ skills compared with conventional training strategies. (13) Also, frequent refreshers with manikinbased simulation may provide cost savings by using less total retraining time as compared with standard retraining intervals. Low-dose, high-frequency (LDHF) training is a new approach to improve clinical knowledge, build and retain competency, and transfer skills into practice after training. (14)

Although a self-learning station for basic life support is one of the possible ways to learn BLS/AED, in a study by Monsieurs $\mathrm{KG}$ et al. nurses achieved adequate compression depths after instructor-led training. (15) It has been proved that training for the implementation of the resuscita-

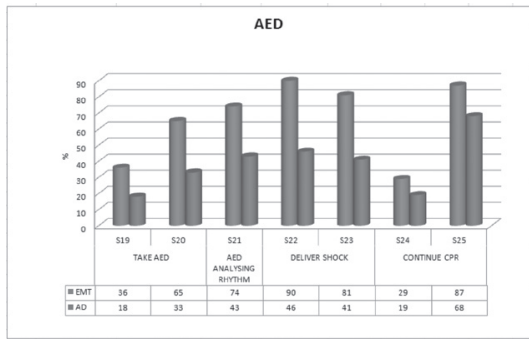

Figure 3. Automated external defibrillation (AED), properly implemented steps

$\mathrm{AD}$, ambulance driver; CPR, cardiopulmonary resuscitation; EMT, emergency medical technician

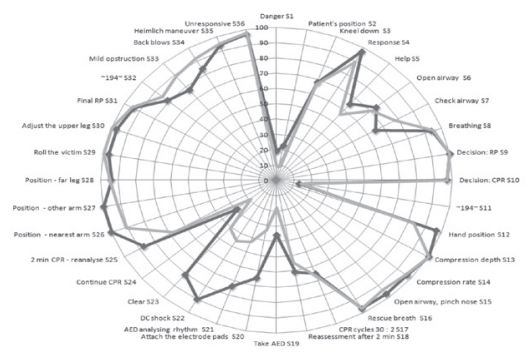

Figure 6. Comparative overview of the percent scored of step-by-step BLS/AED sequence between EMTs and ADs $(p<$ 0.001)

Black line - emergency medical technicians; gray line - ambulance drivers; numbers and texts around the circle $=$ sequence number (1-36) and action; numbers 1-120 inside circle $=$ percentage $(1-100 \%)$

$\mathrm{AD}$, ambulance driver; ALS, advanced life support; BLS, basic life support; CPR, cardiopulmonary resuscitation; DC, direct current; EMT, emergency medical technician; RP, recovery position.

tion procedure cannot be achieved only by reading or listening to theoretical concepts, but that practice is essential. $(16,17)$ Traditional training packages for both lay and healthcare rescuers have focused on face-to-face training with an instructor, although evidence is emerging that the use of self-directed learning and digital media may be as effective either as a replacement or with reduced face-to-face time. (16) Good quality early CPR influences the outcome; however, the best way to prepare and keep laypersons' and health professionals' skills remains controversial. (17) Future research should be focused on finding more effective, shorter, and cheaper BLS / AED training. Through better meas- 
urement, training and systems-improvement processes of CPR quality, we can have a significant impact on survival from $\mathrm{CA}$ and eliminate the gap between current and optimal outcomes.

\section{LIMITATIONS}

Our study has several limitations.

The main problem is a delay in Serbian translation of the current BLS guidelines. As the official and native language in Serbia is Serbian, most of the respondents with insufficient command of foreign lan- guages learn about the current changes in the BLS guidelines with delay.

Our study examined neither the length of the short and long-term maintenance of the acquired knowledge after the training, nor the determining variables that can affect memorizing BLS protocols or their faster forgetting.

Despite the existence of BLS courses for healthcare professionals throughout Serbia, there is still no clear consensus or common standard for this extremely important aspect of education.

Ambulance drivers, although integral parts of EMS teams, both for medical transport and for resuscitation teams, have not been legally recognized yet as team members, and therefore do not possess sufficient motivation during training.

It was not possible to find out whether the respondents in this study were in a position to apply BLS measures in early stages of SCA as witnesses on or off the workplace after the training.

Table 1. Step by step sequence of basic life support/advanced life support (BLS/AED) actions by the trained medical technicians and ambulance drivers during regular training.

\begin{tabular}{lll}
\hline Step Sequence / Action & Implemented \\
\cline { 2 - 2 } & 0 Not 1 Partially 2 Properly \\
\hline
\end{tabular}

IA

S1. DANGER

Safety assessment (rescuer, any bystanders and victim); beware of enviromental danger (electric, gas, water, traffic), personal protective equipment

S2. Place patient supine on a hard, flat surface

S3. Kneel down on one side of the person

S4. RESPONSE

Check response: stimulate (shake shoulders) and speak (ask: Are you all right?)

S5. Unresponsive - shout for help

S6. AIRWAY

Open airway - head tilt-chin lift maneuver

S7. Check airway

S8. BREATHING

Check breathing - look, listen and feel for no more than 10 seconds

S9. DECISION-MAKING PROCESS

Unresponsive, breathing normally - recovery position

S10. Unresponsive and not breathing normally - begin CPR

BLS

S11. $\quad$ 194

Call the emergency services - 194

\section{S12. COMPRESSION}

Hand position on the lower half of the sternum (place the heel of one hand in the centre, place the heel of the other hand on top of the first hand, interlock the fingers)

S13. Compression depth approximately $5 \mathrm{~cm}$ (but not more than $6 \mathrm{~cm}$ )

S14. Compression rate of 100-120/ min, minimal interruption in chest compression $<10$ seconds, equal compression : relaxation

S15. VENTILATION

Head Tilt-Chin Lift maneuver, pinch nose, place and seal lips over the manikin's mouth

S16. Each rescue breath should last approximately 1 second

S17. CPR CYCLES

Chest compression to ventilation ratio of $30: 2$

S18 Reassessment of during CPR - after every 5 cycles or 2 minutes of CPR, check for normal breathing AED 
S19. TAKE AED

Send for AED

S20. Switch on the AED, attach the electrode pads on the manikin's bare chest

S21. AED ANALYSING RHYTHM

Follow the spoken/visual directions - AED is analysing the rhythm

S22. DELIVER SHOCK

If a shock is indicated, deliver shock

S23. Ensure that nobody is touching the victim - CLEAR

S24. CONTINUE CPR

If no shock is indicated, continue CPR

S25. 2 min of CPR before the next voice prompt to reanalyse the rhythm

RP

S26. POSITION VICTIM

Place the person's arm nearest to rescuer out at right angles to his body, elbow bent with the hand palm-up

S27. Bring the far arm across the chest, and hold the back of the hand against the victim's cheek nearest to rescuer

S28. With your other hand, grasp the far leg just above the knee and pull it up, keeping the foot on the ground

S29. ROLL THE VICTIM TOWARDS THE RESCUER

Keeping his hand pressed against his cheek, pull on the far leg to roll the victim towards you on to his side

S30. Adjust the upper leg so that both the hip and knee are bent at right angles

S31. FINAL RECOVERY POSITION

Tilt the head back to make sure that the airway remains open

S32. 194

Call 194 for an ambulance

FBAO

S33. MILD OPSTRUCTION

Encourage to cough

S34. SEVERE OBSTRUCTION

Give up to 5 back blows

S35. Ineffective back blows - give up to 5 abdominal thrusts

S36. UNRESPONSIVE

Start CPR

TOTAL POINTS

AED, automated external defibrillation; BLS, basic life support; CPR, cardiopulmonary resuscitation; FBAO, foreign body airway obstruction; IA, initial assessment; RP, recovery position 
Table 2. Practical implementation of BLS skills (step by step S1-S36) of EMTs and ADs, individually and collectively

\begin{tabular}{|c|c|c|c|c|c|}
\hline $\begin{array}{l}\text { Step } \\
\text { Chi-Square Tests Sig.* }\end{array}$ & Group & $\begin{array}{l}\text { Not implemented } \\
\text { procedures n (\%) }\end{array}$ & $\begin{array}{l}\text { Partially implemented } \\
\text { procedures n (\%) }\end{array}$ & $\begin{array}{l}\text { Properly implemented } \\
\text { procedures } \mathbf{n}(\%)\end{array}$ & Total n (\%) \\
\hline S1 & EMT & $18(58.1)$ & $7(22.6)$ & $6(19.4)$ & $31(100.0)$ \\
\hline \multirow[t]{2}{*}{$\mathrm{P}=0.643$} & $\mathrm{AD}$ & $50(79.4)$ & $7(11.1)$ & $6(9.5)$ & $63(100.0)$ \\
\hline & Total & $68(72.3)$ & $14(14.9)$ & $12(12.8)$ & $94(100.0)$ \\
\hline S2 & EMT & $18(58.1)$ & $6(19.4)$ & 7 (22.6) & $31(100.0)$ \\
\hline \multirow[t]{2}{*}{$\mathrm{P}=0.086$} & $\mathrm{AD}$ & $43(68.3)$ & $14(22.2)$ & $6(9.5)$ & $63(100.0)$ \\
\hline & Total & $61(64.9)$ & $20(21.3)$ & $13(13.8)$ & $94(100.0)$ \\
\hline S3 & EMT & $5(16.0)$ & $5(16.0)$ & $21(67.7)$ & $31(100.0)$ \\
\hline \multirow[t]{2}{*}{$\mathrm{P}=0.604$} & $\mathrm{AD}$ & $5(7.9)$ & $16(25.4)$ & $42(66.7)$ & $63(100.0)$ \\
\hline & Total & $10(10.6)$ & $21(22.3)$ & $63(67.0)$ & $94(100.0)$ \\
\hline S4 & EMT & $0(0.0)$ & $1(3.2)$ & 30 (96.8) & $31(100.0)$ \\
\hline \multirow[t]{2}{*}{$\mathrm{P}=0.910$} & $\mathrm{AD}$ & $0(0.0)$ & $7(11.1)$ & $56(88.9)$ & $63(100.0)$ \\
\hline & Total & $0(0.0)$ & $8(8.5)$ & $20(64.5)$ & $31(100.0)$ \\
\hline S5 & EMT & $2(6.5)$ & $9(29.0)$ & $30(96.8)$ & $31(100.0)$ \\
\hline \multirow[t]{2}{*}{$\mathrm{P}=0.108$} & $\mathrm{AD}$ & $5(7.9)$ & $23(36.5)$ & $35(55.6)$ & $63(100.0)$ \\
\hline & Total & $7(7.4)$ & $32(34.0)$ & 55 (58.5) & $94(100.0)$ \\
\hline S6 & EMT & $3(9.7)$ & $5(16.1)$ & $23(74.2)$ & $31(100.0)$ \\
\hline \multirow[t]{2}{*}{$\mathrm{P}=0.203$} & $\mathrm{AD}$ & $16(25.4)$ & $2(3.2)$ & $45(71.4)$ & $63(100.0)$ \\
\hline & Total & $19(20.2)$ & $7(7.4)$ & $68(72.3)$ & $94(100.0)$ \\
\hline S7 & EMT & $2(6.5)$ & $9(29.0)$ & $20(64.5)$ & $31(100.0)$ \\
\hline \multirow[t]{2}{*}{$\mathrm{P}=0.595$} & $\mathrm{AD}$ & $2(3.2)$ & $12(19.0)$ & $49(77.8)$ & $63(100.0)$ \\
\hline & Total & $4(4.3)$ & $21(22.3)$ & $69(73.4)$ & $94(100.0)$ \\
\hline S8 & EMT & $0(0.0)$ & $2(6.5)$ & $29(93.5)$ & $31(100.0)$ \\
\hline \multirow[t]{2}{*}{$\mathrm{P}=0.976$} & $\mathrm{AD}$ & $0(0.0)$ & $3(4.8)$ & $60(95.2)$ & $63(100.0)$ \\
\hline & Total & $0(0.0)$ & $5(5.3)$ & 89 (94.7) & $94(100.0)$ \\
\hline S9 & EMT & $0(0.0)$ & $0(0.0)$ & $31(100.0)$ & $31(100.0)$ \\
\hline \multirow[t]{2}{*}{$\mathrm{P}=1.000$} & $\mathrm{AD}$ & $0(0.0)$ & $0(0.0)$ & $63(100.0)$ & $63(100.0)$ \\
\hline & Total & $0(0.0)$ & $0(0.0)$ & $94(100.0)$ & $94(100.0)$ \\
\hline S10 & EMT & $0(0.0)$ & $1(3.2)$ & $30(96.8)$ & $31(100.0)$ \\
\hline \multirow[t]{2}{*}{$\mathrm{P}=0.826$} & $\mathrm{AD}$ & $0(0.0)$ & $2(3.2)$ & $61(96.8)$ & $63(100.0)$ \\
\hline & Total & $0(0.0)$ & $3(3.2)$ & $91(96.8)$ & $94(100.0)$ \\
\hline S11 & EMT & $25(80.6)$ & $2(6.5)$ & $4(12.9)$ & $31(100.0)$ \\
\hline \multirow[t]{2}{*}{$\mathrm{P}=0.452$} & $\mathrm{AD}$ & $50(79.4)$ & $4(6.3)$ & $9(14.3)$ & $63(100.0)$ \\
\hline & Total & $75(79.8)$ & $6(6.4)$ & $13(13.8)$ & $94(100.0)$ \\
\hline S12 & EMT & $1(3.2)$ & $0(0.0)$ & $30(96.8)$ & $31(100.0)$ \\
\hline \multirow{2}{*}{$\mathrm{P}=0.534$} & $\mathrm{AD}$ & $7(11.1)$ & $4(6.3)$ & $52(82.5)$ & $63(100.0)$ \\
\hline & Total & $8(8.5)$ & $4(4.3)$ & $82(87.2)$ & $94(100.0)$ \\
\hline S13 & EMT & $0(0.0)$ & $0(0.0)$ & $31(100.0)$ & $31(100.0)$ \\
\hline \multirow[t]{2}{*}{$\mathrm{P}=1.000$} & $\mathrm{AD}$ & $0(0.0)$ & $0(0.0)$ & $63(100.0)$ & $63(100.0)$ \\
\hline & Total & $0(0.0)$ & $0(0.0)$ & $94(100.0)$ & $94(100.0)$ \\
\hline S14 & EMT & $0(0.0)$ & $1(3.2)$ & $30(96.8)$ & $31(100.0)$ \\
\hline \multirow[t]{2}{*}{$\mathrm{P}=0.536$} & $\mathrm{AD}$ & $0(0.0)$ & $4(4.8)$ & $60(95.2)$ & $63(100.0)$ \\
\hline & Total & $0(0.0)$ & $4(4.3)$ & 90 (95.7) & $94(100.0)$ \\
\hline S15 & EMT & $0(0.0)$ & $1(3.2)$ & $30(96.8)$ & $31(100.0)$ \\
\hline \multirow[t]{2}{*}{$\mathrm{P}=0.494$} & $\mathrm{AD}$ & $1(1.6)$ & $3(4.8)$ & $59(93.7)$ & $63(100.0)$ \\
\hline & Total & $1(1.1)$ & $4(4.3)$ & 89 (94.7) & $94(100.0)$ \\
\hline S16 & EMT & $0(0.0)$ & $1(3.2)$ & $30(96.8)$ & $31(100.0)$ \\
\hline \multirow{2}{*}{$\mathrm{P}=0.216$} & $\mathrm{AD}$ & $1(1.6)$ & $3(4.8)$ & 59 (93.7) & $63(100.0)$ \\
\hline & Total & $1(1.1)$ & $4(4.3)$ & 89 (94.7) & $94(100.0)$ \\
\hline S17 & EMT & $1(3.2)$ & $10(32.3)$ & $20(96.8)$ & $31(100.0)$ \\
\hline \multirow[t]{2}{*}{$\mathrm{P}=0.431$} & $\mathrm{AD}$ & $1(1.6)$ & $20(31.7)$ & $42(66.7)$ & $63(100.0)$ \\
\hline & Total & $2(2.1)$ & $30(31.9)$ & $62(66.0)$ & $94(100.0)$ \\
\hline S18 & EMT & $3(9.7)$ & $9(29.0)$ & $19(91.3)$ & $31(100.0)$ \\
\hline \multirow{2}{*}{$\mathrm{P}=0.808$} & $\mathrm{AD}$ & $8(12.7)$ & $22(34.9)$ & $33(52.4)$ & $63(100.0)$ \\
\hline & Total & $11(11.7)$ & $31(33.0)$ & $52(55.3)$ & $94(100.0)$ \\
\hline
\end{tabular}




\begin{tabular}{|c|c|c|c|c|c|}
\hline S19 & EMT & $12(38.7)$ & $8(25.8)$ & $11(35.5)$ & $31(100.0)$ \\
\hline \multirow[t]{2}{*}{$\mathrm{P}=0.315$} & $\mathrm{AD}$ & $35(55.6)$ & $17(27.0)$ & $11(17.5)$ & $63(100.0)$ \\
\hline & Total & $47(50.0)$ & 25 (26.6) & $22(23.4)$ & $94(100.0)$ \\
\hline S20 & EMT & $2(6.5)$ & $9(29.0)$ & $20(64.5)$ & $31(100.0)$ \\
\hline \multirow[t]{2}{*}{$\mathrm{P}=0.0001$} & $\mathrm{AD}$ & 27 (42.9) & $15(23.8)$ & $21(33.3)$ & $63(100.0)$ \\
\hline & Total & $23(30.9)$ & $24(25.5)$ & $41(43.6)$ & $94(100.0)$ \\
\hline S21 & EMT & $1(3.2)$ & $7(22.6)$ & $23(74.2)$ & $31(100.0)$ \\
\hline \multirow[t]{2}{*}{$\mathrm{P}=0.001$} & $\mathrm{AD}$ & $21(33.3)$ & $15(23.8)$ & 27 (42.9) & $63(100.0)$ \\
\hline & Total & $22(23.4)$ & $22(23.4)$ & $50(53.2)$ & $94(100.0)$ \\
\hline S22 & EMT & $0(0.0)$ & $3(9.7)$ & $28(90.3)$ & $31(100.0)$ \\
\hline \multirow[t]{2}{*}{$\mathrm{P}=0.001$} & $\mathrm{AD}$ & $21(33.3)$ & $13(20.6)$ & $29(46.0)$ & $63(100.0)$ \\
\hline & Total & $21(22.3)$ & $16(17.0)$ & $57(60.6)$ & $94(100.0)$ \\
\hline S23 & EMT & $2(6.5)$ & $4(12.9)$ & $25(80.6)$ & $31(100.0)$ \\
\hline \multirow[t]{2}{*}{$\mathrm{P}=0.003$} & $\mathrm{AD}$ & $23(36.5)$ & $14(22.2)$ & $26(41.3)$ & $63(100.0)$ \\
\hline & Total & $25(26.6)$ & $18(19.1)$ & $51(54.3)$ & $94(100.0)$ \\
\hline S24 & EMT & $20(64.5)$ & $2(6.5)$ & $9(29.0)$ & $31(100.0)$ \\
\hline \multirow[t]{2}{*}{$\mathrm{P}=0.868$} & $\mathrm{AD}$ & $42(66.7)$ & $12(19.0)$ & $9(14.3)$ & $63(100.0)$ \\
\hline & Total & $62(66.0)$ & $14(14.9)$ & $18(19.1)$ & $94(100.0)$ \\
\hline S25 & EMT & $3(9.7)$ & $1(3.2)$ & $27(87.1)$ & $31(100.0)$ \\
\hline \multirow[t]{2}{*}{$\mathrm{P}=0.470$} & $\mathrm{AD}$ & $12(19.0)$ & $8(12.7)$ & $43(68.3)$ & $63(100.0)$ \\
\hline & Total & $62(16.0)$ & $14(19.6)$ & $18(74.5)$ & $94(100.0)$ \\
\hline S26 & EMT & $0(0.0)$ & $0(0.0)$ & $31(100.0)$ & $31(100.0)$ \\
\hline \multirow[t]{2}{*}{$\mathrm{P}=0.334$} & $\mathrm{AD}$ & $2(3.2)$ & $4(6.3)$ & $57(90.5)$ & $63(100.0)$ \\
\hline & Total & $2(2.1)$ & $4(4.3)$ & 88 (93.6) & $94(100.0)$ \\
\hline S27 & EMT & $0(0.0)$ & $0(0.0)$ & $31(100.0)$ & $31(100.0)$ \\
\hline \multirow[t]{2}{*}{$\mathrm{P}=0.351$} & $\mathrm{AD}$ & $2(3.2)$ & $3(4.8)$ & $58(92.0)$ & $63(100.0)$ \\
\hline & Total & $2(2.1)$ & $3(3.2)$ & 89 (94.7) & $94(100.0)$ \\
\hline S28 & EMT & $2(6.5)$ & $0(0.0)$ & $29(93.5)$ & $31(100.0)$ \\
\hline \multirow[t]{2}{*}{$\mathrm{P}=0.207$} & $\mathrm{AD}$ & $2(3.2)$ & $1(1.6)$ & $60(95.2)$ & $63(100.0)$ \\
\hline & Total & $4(4.3)$ & $1(1.1)$ & $89(94.7)$ & $94(100.0)$ \\
\hline S29 & EMT & $0(0.0)$ & $1(3.2)$ & $30(96.8)$ & $31(100.0)$ \\
\hline \multirow[t]{2}{*}{$\mathrm{P}=0.316$} & $\mathrm{AD}$ & $0(0.0)$ & $0(0.0)$ & $63(100.0)$ & $63(100.0)$ \\
\hline & Total & $0(0.0)$ & $1(1.1)$ & $93(98.9)$ & $94(100.0)$ \\
\hline S30 & EMT & $0(0.0)$ & $1(3.2)$ & $30(96.8)$ & $31(100.0)$ \\
\hline \multirow[t]{2}{*}{$\mathrm{P}=0.316$} & $\mathrm{AD}$ & $0(0.0)$ & $0(0.0)$ & $63(100.0)$ & $63(100.0)$ \\
\hline & Total & $0(0.0)$ & $1(1.1)$ & 93 (98.9) & $94(100.0)$ \\
\hline S31 & EMT & $2(6.5)$ & $0(0.0)$ & $29(93.5)$ & $31(100.0)$ \\
\hline \multirow{2}{*}{$\mathrm{P}=0.008$} & $\mathrm{AD}$ & $1(1.6)$ & $2(3.2)$ & $60(95.2)$ & $63(100.0)$ \\
\hline & Total & $3(3.2)$ & $2(2.1)$ & 89 (97.7) & $94(100.0)$ \\
\hline S32 & EMT & $1(3.2)$ & $5(16.1)$ & $25(80.6)$ & $31(100.0)$ \\
\hline \multirow[t]{2}{*}{$\mathrm{P}=0.976$} & $\mathrm{AD}$ & $7(11.1)$ & $2(3.2)$ & $54(85.7)$ & $63(100.0)$ \\
\hline & Total & $8(8.5)$ & $7(16.1)$ & $79(77.4)$ & $94(100.0)$ \\
\hline S33 & EMT & $2(6.5)$ & $5(16.1)$ & $24(80.6)$ & $31(100.0)$ \\
\hline \multirow[t]{2}{*}{$\mathrm{P}=0.591$} & $\mathrm{AD}$ & $5(7.9)$ & $2(3.2)$ & $56(88.9)$ & $63(100.0)$ \\
\hline & Total & $7(7.4)$ & $7(7.4)$ & $80(85.1)$ & $94(100.0)$ \\
\hline S34 & EMT & $1(3.2)$ & $4(12.9)$ & $26(83.9)$ & $31(100.0)$ \\
\hline \multirow[t]{2}{*}{$\mathrm{P}=0.606$} & $\mathrm{AD}$ & $2(3.2)$ & $3(4.8)$ & $58(92.1)$ & $63(100.0)$ \\
\hline & Total & $3(3.2)$ & $7(7.4)$ & $84(89.4)$ & $94(100.0)$ \\
\hline S35 & EMT & $1(3.2)$ & $1(3.2)$ & $29(93.5)$ & $31(100.0)$ \\
\hline \multirow[t]{2}{*}{$\mathrm{P}=0.075$} & $\mathrm{AD}$ & $0(0.0)$ & $3(4.8)$ & $60(95.2)$ & $63(100.0)$ \\
\hline & Total & $1(1.1)$ & $4(4.3)$ & $89(84.7)$ & $94(100.0)$ \\
\hline S36 & EMT & $0(0.0)$ & $1(3.2)$ & $30(96.8)$ & $31(100.0)$ \\
\hline \multirow[t]{2}{*}{$\mathrm{P}=0.154$} & $\mathrm{AD}$ & $0(0.0)$ & $1(1.6)$ & $62(98.4)$ & $63(100.0)$ \\
\hline & Total & $0(0.0)$ & $2(2.1)$ & $92(97.9)$ & $94(100.0)$ \\
\hline
\end{tabular}

The bold number represents the largest number and percentage in proper or in not implemented BLS/AED skills (S1-S36) $\mathrm{AD}$, ambulance driver; EMT, emergency medical technician 
1. Taniguchi D, Baernstein A, Nichol G. Cardiac arrest: a public health perspective. Emerg Med Clin North Am 2012;30:1-12.

2. Kleinman ME, Brennan EE, Goldberger ZD, Swor RA, Terry M, Bobrow BJ, et al. Part 5: Adult basic life support and cardiopulmonary resuscitation quality: 2015 American Heart Association Guidelines Update for Cardiopulmonary Resuscitation and Emergency Cardiovascular Care. Circulation 2015;132(18 Suppl 2):S414-S35.

3. Soreide E, Morrison L, Hillman K, Monsieurs K, Sunde K, Zideman D, et al. The formula for survival in resuscitation. Resuscitation 2013;84:1487-93.

4. Greif R, Lockey AS, Conaghan P, Lippert A, De Vries W, Monsieurs KG, on behalf of the Education and implementation of resuscitation section Collaborators. European Resuscitation Council Guidelines for Resuscitation 2015:Section 10. Education and implementation of resuscitation. Resuscitation 2015;95:288-301.

5. Perkins G, Handley A, Koster R, Castrén M, Smyth M, Olasveengen T, et al. European Resuscitation Council Guidelines for Resuscitation 2015: Section 2. Adult basic life support and automated external defibrillation. 2015;95:85-8.

6. Chan TK, Wan KA, Chan JCK, Lam HKC, Wrong YT, Kan PG. New era of CPR: application of i-technology in resuscitation. Hong Kong J Em Med 2012;19:305-11.

7. Hendry JM. Poor Quality CPR Often Performed by Trained Medical Professionals. Available from: http://www.merginet.com/index. cfm?searched=/clinical/cardiac/PoorQualityCPR.cfm. Accessed: November 18, 2006

8. Miotto HC, Goulart EMA, Amaral CF, Moreira MCV. Influência do subsídio financeiro e do local da realização do Curso de Suporte Avançado de Vida em Cardiologia, no aprendizado da emergência cardiovascular. Arq Bras Cardiol 2008; 90(3):191-4.

9. Batcheller AM, Brennan RT, Braslow A, Urrutia A, Kaye W. Cardiopulmonary resuscitation performance of subjects over forty is better following half-hour video self-instruction compared to traditional four-hour classroom training. Resuscitation 2000;43(2):10110.

10. Toner P, Connoly M, Laverty L, McGrath P, Connoly D, McCluskey DR. Teaching basic life support to school children using medical students and teachers in a "peer-training" model-results of the "ABC for life" programme. Resuscitation 2007;75:169-75.

11.11. Garcia Vega FJ, Montero Perez FJ, Encinas Puente RM. Editorial: Schools: a community setting to target for training in cardiopulmonary resuscitation. Emergencias 2008;20:223-5.

12. Sutton RM, Niles D, Meaney PA, Aplenc R, French B, Abella BS, et al. Low-dose, high-frequency CPR training improves skill retention of in-hospital pediatric providers. Pediatrics 2011;128:e145-51.

13. Niles D, Sutton RM, Donoghue A, Kalsi MR, Robertset K, Boyle L, et al. "Rolling Refreshers": a novel approach to maintain CPR psychomotor skill competence. Resuscitation 2009;80:909-12.

14. Willcox M, Harrison H, Asiedu A, Nelson A, Gomez P, LeFevre A. Incremental cost and cost-effectiveness of low-dose, high-frequency training in basic emergency obstetric and newborn care as compared to status quo: part of a cluster-randomized training intervention evaluation in Ghana. Global Health 2017;13(1):88. doi: 10.1186/s12992-017-0313-x.

15. Monsieurs KG, De Regge M, Schelfout S, D 'Hondt F, Mpotos N, Valcke M, et al. Efficacy of a self-learning station for basic life support refresher training in a hospital: a randomized controlled trial. Eur J Emerg Med 2012;19(4):214-9.

16. Chung CH, Siu AY, Po LL, Lam CY, Wong PC. Comparing the effectiveness of video self-instruction versus traditional classroom instruction targeted at cardiopulmonary resuscitation skills for laypersons: a prospective randomised controlled trial. Hong Kong Med J 2010;16:165-70.

17. Wick L, Kramer-Johansen J, Myklebust H, Sorebo H, Svensson L, Fellows B, et al. Quality of cardiopulmonary resuscitation during out-of-hospital cardiac arrest. JAMA 2005;293(3):299-304. 